\title{
A Climate Change Capitalisation Knowledge Inventory Platform
}

\author{
Hermann KLUG, Richard SCHÖRGHOFER and Steffen REICHEL \\ Interfaculty Department of Geoinformatics - Z_GIS, \\ University of Salzburg / Austria · hermann.klug@sbg.ac.at
}

This contribution was double-blind reviewed as full paper.

\begin{abstract}
In the past decades, climate changes became increasingly noticed. As a result of these changes, many extreme events such as flooding and droughts occur. These have an expected increasing impact on society and the environment. Especially the Alps are affected with a stronger increasing temperature compared to the rest of Europe. As a societal reaction, adaptation strategies and tools have been launched. Among the adaptation tools are web-based adaptation platforms, which are assumed to be important governance tools. They support knowledge brokerage, awareness raising, capacity building, and crosslevel coordination. Within this manuscript we identify available platforms and previous Alpine Space Programme projects and their interdisciplinary and cross-subject climate change related information. We analyse available portals and elaborate design and user requirements for the Climate Change Knowledge Inventory Platform developed here. We found that many previously developed platforms integrate similar information, but automated information exchange between platforms is scarce due to interoperability limitations. To avoid these double works of entering the same findings again, our developed catalogue service for the web solution ensures standard compliant information provision to enable interoperability and thus the exchange of climate change information across platforms.
\end{abstract}

\section{Introduction}

In the past decades, climate changes became increasingly noticed in Europe (EUROPEAN ENVIRONMENT AGENCY 2009, BENISTON \& StePHENSON 2004, BENISTON 2012). Especially the Alps are affected with a stronger increasing temperature compared to the rest of Europe (NOGUÉS-BRAVO et al. 2007). This recognised trend of increasing temperature and a change in precipitation pattern is underpinned by e.g. AUER et al. (2007) and BENISTON and DIAZ (2004). The inter-annual climate variability of temperature is expected to increase in the near future, while the precipitation pattern is also becoming more complex and most importantly - extreme (SCHÄR et al. 2004, NORBIATO et al. 2007).

The changes in precipitation and snowfall put many of the Alpine skiing destinations at risk in providing their services (FALK 2013). Additionally, a loss in glacier mass volume is 
expected to decrease or halt summer discharge altogether, and reduce water availability inside and outside the alpine region over the next decades (PAUL et al. 2007). High temperatures cause not only glacier but also mountain permafrost melting (KÄÄB et al. 2007), and increase the risks on debris flows, landslides, and rock fall (ALLEN \& HUGGEL 2013). The before mentioned hazards also affect the tourism sector (BECKEN 2013) and thus have economic impacts on the respective regions (AAHEIM et al. 2012). In line with the changing precipitation pattern a higher frequency of drought periods in the summer is expected (BRIFFA et al. 2009). Impacts are expected on flora and fauna species distribution or biodiversity (VITTOZ et al. 2013), forests (LINDNER et al. 2002), soils (CASSAGNE et al. 2008), land use/land cover including agriculture (PIELKE SR et al. 2007), and general threats such as fires (WASTL et al. 2013) or stress to buildings (CHRISTENSON et al. 2006).

As a societal reaction, mitigation and adaptation strategies, methods, scenarios and tools have been launched (FALLOON \& BETTS 2010). Scenarios on European adaptation strategies with re-active or pro-active planning, including cost-effectiveness, have been facilitated by, for instance, by DE VRIES (2010). Adaptation strategies have been set up at European level (http://ec.europa.eu/clima/policies/adaptation), and for the European member states at national level (BIESBROEK et al. 2010). Among the adaptation strategies of interest in this manuscript are web-based adaptation platforms. These are assumed to be important governance tools. They support knowledge brokerage, awareness raising, capacity building, and cross-level coordination.

With respect to the climate change impacts (CCI) and climate change adaptation (CCA) strategies, the Alps can be clearly separated from other regions. The Alpine climate change differences origin in the high orographic, topographic and climatological complexities. These cause a distinct analysis of climate change impacts and adaptation strategies across but also within the Alps. Despite the Alpine Space being exposed to similar climate changes, and thus many of the adaptation strategies can be transferred from one region to another, regional spatial planning priorities for adaptation activities need to be identified and tailored to the specific regional importance of climate sensitivities (RANNOW et al. 2010). Thus it becomes evident that climate change, especially when considered on a regional level, has a specific spatial component.

Due to this spatial component, many region specific climate change impacts and adaptation portals have been developed (e.g. Baltic Sea). The regions reflect the specific vulnerable subjects (e.g. forests or water), and the intended operational scale of action (e.g. European and national level). All platforms as outlined below have already developed useful multilingual or monolingual information on potentially transferable adaptation strategies that are scattered across Europe and platforms. Since adaptation tools are in principle transferable and thus offer a valuable link between the different political levels and scale dependent region, integration and automated exchange of present knowledge and tools is needed to avoid double work in entering the same findings again.

To promote content coordination and cross-integration of platforms, common rules need to be employed. These rules rely on internationally accepted standards (e.g. ISO, OGC, INSPIRE) and developments to ensure proper coexistence and exchange possibilities of data, metadata, and information. Thus, the overall objective of this work is to provide available - but presently scattered and inaccessible - information on climate (change) impacts, to visualise already available knowledge about where (location) what is happening (e.g. temperature increase), and to answer the question of why (specific impact) and how to 
adapt (specific countermeasures and action strategies) against this CCI. Pilot sites provide examples where countermeasures (adaptation strategies) have been successfully implemented and explain who (responsible person) has done something where (spatial changes, implemented actions). Based on contributions from the C3-Alps consortium we demonstrate a framework for the CCI and CCA information structuring and organisation in a Climate Change Capitalisation Knowledge Inventory Portal (C3-KIP), where end users can search, discover, and analyse CCI and CCA strategies according to sectors, topics, and regions.

\section{Methods}

\subsection{Inventory of present information portals}

Despite that we know the Alps contain special impacts and thus adaptation strategies on climate change, we discover existing European wide platforms to identify the techniques and methodologies used to transport information on CCI and CCA (Tab. 1). The platforms have been jointly discovered by partners from the C3-Alps consortium but are not complete due to space limitations. We capitalise already available Alpine specific knowledge from previous Alpine Space Programme (ASP) projects (Tab. 2), and together with the end users, extract the most important information from them.

Tab. 1: Available climate change platforms

\begin{tabular}{|c|c|}
\hline Name of the platform & Content \\
\hline $\begin{array}{l}\text { Mountain Research } \\
\text { Initiative }\end{array}$ & $\begin{array}{l}\text { MRI promotes and coordinates global change research in mountain } \\
\text { regions all over the world. }\end{array}$ \\
\hline weADAPT & $\begin{array}{l}\text { weADAPT is an 'open space' on climate adaptation topics including the } \\
\text { synergies with mitigation allowing practitioners, researchers and policy } \\
\text { makers to access credible, high quality information and to share } \\
\text { experiences and lessons learnt. }\end{array}$ \\
\hline on_alp_exchange & $\begin{array}{l}\text { The AdaptAlp experts exchange programme has been designed to } \\
\text { exchange personal experiences. }\end{array}$ \\
\hline Climate Adapt & $\begin{array}{l}\text { The European Climate Adaptation Platform aims to support Europe in } \\
\text { adapting to climate change. }\end{array}$ \\
\hline $\begin{array}{l}\text { The World Bank Climate } \\
\text { Change Knowledge } \\
\text { Portal }\end{array}$ & $\begin{array}{l}\text { The Climate Change Knowledge Portal (CCKP) is a central hub of } \\
\text { information, data and reports about climate change around the world. }\end{array}$ \\
\hline $\begin{array}{l}\text { Goddard Earth Science } \\
\text { Data and Information } \\
\text { Services Center }\end{array}$ & $\begin{array}{l}\text { Giovanni is a NASA Web application aiming at a simple, intuitive way } \\
\text { to visualize, analyse, and access vast amounts of Earth science remote } \\
\text { sensing data, particularly from satellites, without having to download } \\
\text { the data. }\end{array}$ \\
\hline $\begin{array}{l}\text { Governance of Climate } \\
\text { Change Adaptation: } \\
\text { National Strategies and } \\
\text { their Implementation }\end{array}$ & $\begin{array}{l}\text { Selected information from Swiss national adaptation strategies } \\
\text { provided by the Swiss Federal Institute for Forest, Snow and } \\
\text { Landscape Research WSL. }\end{array}$ \\
\hline $\begin{array}{l}\text { Anpassung an den } \\
\text { Klimawandel }\end{array}$ & $\begin{array}{l}\text { Swiss information on climate change and adaptation provided by } \\
\text { BAFU Switzerland in German language. }\end{array}$ \\
\hline
\end{tabular}


Tab. 1 (continued)

\begin{tabular}{|c|c|}
\hline Name of the platform & Content \\
\hline $\begin{array}{l}\text { Adaptation to the Spatial } \\
\text { Impacts of Climate } \\
\text { Change }\end{array}$ & $\begin{array}{l}\text { The Strategic Initiative Cluster "Adaptation to the Spatial Impacts of } \\
\text { Climate Change" (SicAdapt) comprises eight transnational projects } \\
\text { with almost } 100 \text { project partners and combines their efforts for } \\
\text { promoting and achieving effective climate adaptation throughout NW } \\
\text { Europe. }\end{array}$ \\
\hline mountain.TRIP & $\begin{array}{l}\text { mountain.TRIP provides readily accessible and understandable } \\
\text { interdisciplinary mountain research-based information for sustainable } \\
\text { development in mountain regions. }\end{array}$ \\
\hline The Climatemeter & $\begin{array}{l}\text { The Climatemeter provides inspiration for which methods to use when } \\
\text { mapping the risks of flooding within regions or municipalities in } \\
\text { Denmark. }\end{array}$ \\
\hline Klimatilpasning & $\begin{array}{l}\text { This platform presents basic knowledge required for adapting to } \\
\text { climate change, provided by the Norwegian Ministry of Environment. }\end{array}$ \\
\hline UKCIP & $\begin{array}{l}\text { This platform provides a range of tools, methods and guidance to help } \\
\text { to assess the impacts, minimise the risks, or exploit any opportunities } \\
\text { from the changing climate. }\end{array}$ \\
\hline Waldwissen & Climate change and adaptation knowledge on forests. \\
\hline $\begin{array}{l}\text { Climate Change } \\
\text { Collaboratory (Triple-C) }\end{array}$ & $\begin{array}{l}\text { The Climate Change Collaboratory (Triple-C) aims at strengthening } \\
\text { the relations between environmental stakeholders, recognising the need } \\
\text { for climate change adaptation and mitigation, but differ in their specific } \\
\text { worldviews, goals and agendas. }\end{array}$ \\
\hline $\begin{array}{l}\text { Climate Change Media } \\
\text { Watch }\end{array}$ & $\begin{array}{l}\text { The Media Watch on Climate Change intends to increase awareness } \\
\text { and the availability of environmental information with a vast amount } \\
\text { and continuously updated news and social media coverage on climate } \\
\text { change and related issues. }\end{array}$ \\
\hline $\begin{array}{l}\text { Klimawandel-Anpassung } \\
\text { in Österreich }\end{array}$ & $\begin{array}{l}\text { This platform provides information on climate change and adaptation } \\
\text { in Austria and beyond. }\end{array}$ \\
\hline $\begin{array}{l}\text { KomPass - } \\
\text { Kompetenzzentrum } \\
\text { Klimafolgen und } \\
\text { Anpassung }\end{array}$ & $\begin{array}{l}\text { An information resource at the interface of climate impact research, } \\
\text { society, and policy making, and supporting implementation of the } \\
\text { German Adaptation Strategy with vital tools and guidelines on } \\
\text { adaptation practice. }\end{array}$ \\
\hline $\begin{array}{l}\text { KomPass TATENBANK } \\
\text { and KLIMALOTSE }\end{array}$ & $\begin{array}{l}\text { The multilingual KomPass Tatenbank and Klimalotse is a German } \\
\text { platform documenting projects and adaptation measures on local to } \\
\text { regional scale. Guidelines exist how to comprehend climate change and } \\
\text { respective CCA. }\end{array}$ \\
\hline
\end{tabular}

\subsection{Baseline inventory}

In the previous ASP period, many sector-based approaches to CCI and CCA have been developed. As a baseline inventory, the former ASP projects provide input for the C3-KIP 'clearing house' (Tab. 2). Most of the sector specific climate change information is scattered on these websites. The constraints related to these knowledge resources are manifold: i) many reports and information resources need to be discovered manually without any search functionality, ii) structured output to compare different resources is not provided, iii) in the latest two years after the project lifetime websites usually disappear since no further 
support/maintenance is provided by the ASP. These limitations result in a loss of valuable information, which needs to be compensated through a knowledge inventory.

Tab. 2: Alpine Space Programme projects on climate change

\begin{tabular}{|c|c|}
\hline Acronym & Title and website \\
\hline AlpHouse & Alpine building culture and ecology, http://www.alphouse.eu/ \\
\hline AdaptAlp & $\begin{array}{l}\text { Adaptation to Climate Change in the Alpine Space, } \\
\text { http://www.adaptalp.org/ }\end{array}$ \\
\hline Alp-Water-Scarce & $\begin{array}{l}\text { Water Management Strategies against Water Scarcity in the Alps; } \\
\mathrm{http} / / / \text { www.alpwaterscarce.eu/ }\end{array}$ \\
\hline ClimAlpTour & $\begin{array}{l}\text { Climate Change and its impact on tourism in the Alpine Space; } \\
\text { http://www.climalptour.eu/ }\end{array}$ \\
\hline CLISP & $\begin{array}{l}\text { Climate Change Adaptation by Spatial Planning in the Alpine Space; } \\
\text { http://www.clisp.eu/ }\end{array}$ \\
\hline ClimChAlp & $\begin{array}{l}\text { Climate Change, Impacts and Adaptation Strategies in the Alpine Space; } \\
\text { http://www.climchalp.org/ }\end{array}$ \\
\hline MANFRED & $\begin{array}{l}\text { Management strategies to adapt Alpine Space forests to climate change } \\
\text { risks; http://www.manfredproject.eu/ }\end{array}$ \\
\hline PARAMOUNT & $\begin{array}{l}\text { imProved Accessibility: Reliability and security of Alpine transport } \\
\text { infrastructure related to mountainous hazards in a changing climate; } \\
\text { http://www.paramount-project.eu/ }\end{array}$ \\
\hline PermaNeT & $\begin{array}{l}\text { Longterm Permafrost Monitoring Network; http://www.permanet- } \\
\text { alpinespace.eu/ }\end{array}$ \\
\hline SILMAS & $\begin{array}{l}\text { Sustainable Instruments for Lakes Management in the Alpine Space; } \\
\text { http://www.silmas.eu/ }\end{array}$ \\
\hline ALP FFIRS & Alpine Forest Fire Warning System; http://www.alpffirs.eu/ \\
\hline
\end{tabular}

\subsection{Synthesis knowledge structure}

In order to cope with the needs for CCA information, an increasing amount of data, metadata and knowledge covering different regions, impacts, topics / sectors and adaptation strategies must be made available, accessible, searchable and sharable across disciplines (e.g. climatology, pedology, hydrology, and the like). To improve the access to and exchange of CCA information for public sector bodies, private companies, NGOs and citizens, aspects of data capturing, organisation, and harmonisation, as well as interoperability with other systems need to be considered. This demands structural specification for the description and harmonisation of climate change information within the Alps, as well as the operation of a corresponding data infrastructure. Technical and syntactic interoperability need to be ensured by open standards such as published by the Open Geospatial Consortium (OGC). Within the following process chain we foresee data providers and consortia offering their spatial data via OGC compliant Web Feature Services, Web Coverage Services or Web Map Services, ensuring that client systems are 
capable of accessing, displaying and harvesting the distributed data (e.g. map viewer from the Climate Adapt website from the European Environment Agency). Despite these maps being a very important medium to transport place based knowledge on CCI and CCA, and us providing these services within the new C3-KIP, we consider metadata search functionalities as our key focus in this manuscript.

The definition of a set of metadata elements is needed to provide end user demanded structured information that describes, explains, locates, or otherwise makes it easier to retrieve, use, or manage datasets, data series, and data services. To ensure the information from previously mentioned ASP projects is comprehensively addressed, a specific metadata schema has been developed for datasets and services. To be standard compliant, this metadata schema is based on the OGC Catalogue Service Web standard (CSW). All defined metadata is based on ISO 19115 (2003). With the C3-Alps project community we developed a specific 'community profile'. A selected set of additional metadata elements defines field sizes and domains for all metadata elements. The rules for creating a community profile follow the ISO 19106 (2004) standard. Additional service-level metadata is used according to the ISO 19119 (2005) standard. From the implementation point of view the metadata for datasets and services were defined in the ISO 19139 (2007), resulting in the eXtensible Stylesheet Definition (XSD) representation. Relying on open source products and open source developments we used the GeoNetwork Opensource editor (OSGEO 2013) to insert, upload, search, view, and download data, documents, images, PDFs and any other topic related content.

\subsection{Knowledge exposure}

Accessing this information in a structured, synthesised, aggregated, and end user defined way, requires a respective design. This online interface needs to comply with the end user demanded functionalities and their way of interfering with the web portal and its tools. In analogy to the SQL query concept, OGC web services query metadata records and their elements in self-descriptive machine readable XML format to expose a data source. We expose the data on a platform designed with Twitter bootstrap and the Play Framework.

\section{$3 \quad$ Results}

Many platforms as outlined in Tab. 1 do not have standardised data offerings. Some websites are based on Content Management Systems, others have a database with structured information on CCA and CCI in the background. However, in both cases, structured interoperability and discovery across platforms is not supported. Some platforms show climate change impact maps (e.g. temperature change). These are either copies of datasets or simple images. The only standardised products we could discover come from the Climate Adapt website of the European Environment Agency, where e.g. spatial datasets are referenced within a GeoNetwork Opensource and maps are discoverable as Web Map Services.

From the ASP projects listed in Tab. 2, the end users discovered a lot of useful information such as pictures, reports, or spatial datasets, which was entered to the CSW according to the ISO 19115 standard and the schema extension. The presently entered $>250$ records provide 
a good starting point to discover available resources on different climate change topics across the Alps. Searching these metadata records is possible with an end user discussed interface outline, where required search options are available. The general portal structure as shown in Fig. 1 starts top-down with some information about the different tools available, followed by the search tool with respectively matching records in a preview result listing. Finally, selected attributes from the $>250$ possible metadata entries per metadata records are presented as downloadable two page information where also resource files like pictures and case study related good practice reports etc. can be downloaded.

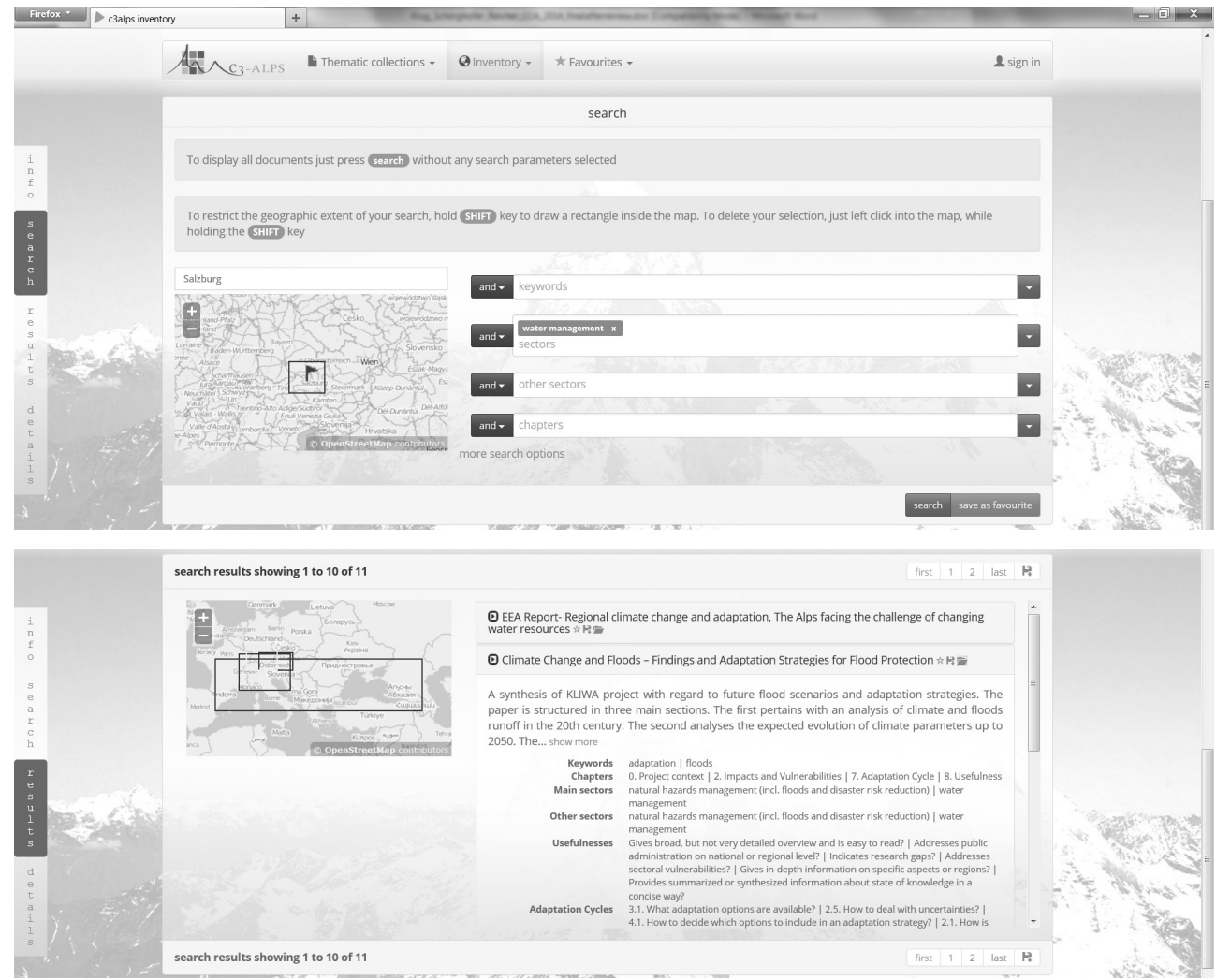

Fig. 1: The C3-KIP search mask (top) and result list (bottom)

\section{Conclusion and Outlook}

The Food and Agriculture Organisation (FAO), the World Food Programme (WFP), the United Nations Environment Programme (UNEP) and more recently the Office for the Coordination of Humanitarian Affairs (OCHA), have combined their research and mapping expertise to develop GeoNetwork Opensource as a common strategy to effectively share their spatial databases including digital maps, satellite images and related information. The agencies make extensive use of computer-based (meta-)data provision tools. They use the 
capacity to access a wide selection of maps and other spatial information stored in different databases around the globe through a single entry point. These developments lead to connected spatial information communities and connected (meta-)data using a modern architecture. Based on the principles of Free and Open Source Software (FOSS), and internationally accepted and open standards for services and protocols (e.g. ISO/TC211 and OGC), this architecture is simultaneously powerful and low cost. This example should be transported to the domain of CCI and CCA, too. The advantage of the web services as discussed in this manuscript is that the participating systems can provide their data in a standardised format and protocol over the internet. Data can stay with the data provider where the respective entries are updated and maintained. Any application or software package can interact dynamically with such data repositories at any time. The data storage schema can be application specific, but is of no further interest, because the data source is to be accessed and queried via the web service. The web service provides all necessary descriptions on how to interact with it. All data sets are accessible via the web service. In such cases the underlying database schema is rather optimized for the application, instead for direct user access. Data processing on the data sets can either happen on the provider or the consumer side, both have the same records available in the same format - which is a foundation in the European Spatial Data Infrastructure (MAGUIRE \& LONGLEY 2005).

Presently, CCA strategies have been developed at European and mainly national level. However, since CCI have a certain spatial-temporal component, CCA strategies need to be tailored to the local landscape level. This will force municipalities to establish respective strategies for their needs. Since the adopted strategies are likely to be transferable to other regions, accessibility for knowledge exchange and transferability to other knowledge portals should be established. With the present developments outlined in this manuscript, the interoperability with other systems is assured by the metadata standards and the publicly available metadata schema extension developed. Local resources can be setup and interconnected with other portals to maximise the beneficial use of scarce labour and knowledge resources at local level.

\section{References}

Aaheim, A., Amundsen, H., Dokken, T. \& Wei, T. (2012), Impacts and adaptation to climate change in European economies. Global Environmental Change, 22 (4), 959-968.

Allen, S. \& HugGel, C. (2013), Extremely warm temperatures as a potential cause of recent high mountain rockfall. Global and Planetary Change, 107, 59-69.

Auer, I., Böhm, R., Jurkovic, A., Lipa, W., Orlik, A., Potzmann, R., Schöner, W., Ungersböck, M., Matulla, C., Briffa, K., Jones, P., Efthymiadis, D., Brunetti, M., Nanni, T., Maugeri, M., Mercalli, L., Mestre, O., Moisselin, J.-M., Begert, M., Müller-Westermeier, G., Kveton, V., Bochnicek, O., Stastny, P., Lapin, M., Szalai, S., Szentimrey, T., Cegnar, T., Dolinar, M., GaJiC-CAPKA, M., ZANinOVIC, K., MAJSTOROVIC, Z. \& NiePlOVA, E. (2007), HISTALP - historical instrumental climatological surface time series of the Greater Alpine Region. International Journal of Climatology, 27 (1), 17-46.

BECKEN, S. (2013), A review of tourism and climate change as an evolving knowledge domain. Tourism Management Perspectives, 6, 53-62. 
Beniston, M. \& DiAZ, H. F. (2004), The 2003 heat wave as an example of summers in a greenhouse climate? Observations and climate model simulations for Basel, Switzerland. Global and Planetary Change, 44 (1-4), 73-81.

Beniston, M. \& Stephenson, D. B. (2004), Extreme climatic events and their evolution under changing climatic conditions. Global and Planetary Change, 44 (1-4), 1-9.

BENISTON, M. (2012), Impacts of climatic change on water and associated economic activities in the Swiss Alps. Journal of Hydrology, 412-413, 291-296.

Biesbroek, G. R., Swart, R. J., Carter, T. R., Cowan, C., Henrichs, T., Mela, H., Morecroft, M. D. \& REY, D. (2010), Europe adapts to climate change: Comparing National Adaptation Strategies. Global Environmental Change, 20 (3), 440-450.

BrifFA, K. R., VAN DER Schrier, G. \& JONES, P. D. (2009), Wet and dry summers in Europe since 1750: evidence of increasing drought. International Journal of Climatology, 29 (13), 1894-1905.

Cassagne, N., Spiegelberger, T., Cécillon, L., Juvy, B. \& Brun, J.-J. (2008), The impact of soil temperature increase on organic matter and faunal properties in a frozen calcareous scree in the French Alps. Geoderma, 146 (1-2), 239-247.

Christenson, M., Manz, H. \& Gyalistras, D. (2006), Climate warming impact on degree-days and building energy demand in Switzerland. Energy Conversion and Management, 47 (6), 671-686.

DE VRIES, A. (2010), European territories confronted with climate change: Awaiting the events or timely preparation? Futures, 42 (8), 825-832.

EUROPEAN ENVIRONMENT AGENCY (2009), Regional climate change and adaptation. The Alps facing the challenge of changing water resources. EEA, Copenhagen.

FALK, M. (2013), A survival analysis of ski lift companies. Tourism Management, 36, 377390.

FAlloON, P. \& BeTtS, R. (2010), Climate impacts on European agriculture and water management in the context of adaptation and mitigation - The importance of an integrated approach. Science of The Total Environment, 408 (23), 5667-5687.

ISO 19106 (2004), Geographic information - Profiles, 32 p.

ISO 19115 (2003), Geographic information - Metadata, 140 p.

ISO 19119 (2005), Geographic information - services v. 1.1, 67 p.

ISO 19139 (2007), Geographic Information - Metadata - XML schema implementation (Encoding of Metadata), $111 \mathrm{p}$.

KäÄB, A., Chiarle, M., Raup, B. \& Schneider, C. (2007), Climate change impacts on mountain glaciers and permafrost. Global and Planetary Change, 56 (1-2), vii-ix.

Lindner, M., Sohngen, B., Joyce, L. A., Price, D. T., Bernier, P. Y. \& Karjalainen, T. (2002), Integrated forestry assessments for climate change impacts. Forest Ecology and Management, 162 (1), 17-136.

Maguire, D. J. \& Longley, P. A. (2005), The emergence of geoportals and their role in spatial data infrastructures. Computers, Environment and Urban Systems, 29 (1), 3-14.

Nogués-Bravo, D., Araújo, M. B., Errea, M. P. \& Martínez-Rica, J. P. (2007), Exposure of global mountain systems to climate warming during the 21st Century. Global Environmental Change, 17 (3-4), 420-428.

Norbiato, D., Borga, M., SANGATI, M. \& Zanon, F. (2007), Regional frequency analysis of extreme precipitation in the eastern Italian Alps and the August 29, 2003 flash flood. Journal of Hydrology, 345(3-4), 149-166.

OSGEO (2013), GeoNetwork Opensource User Manual. Release 2.11.0-SNAPSHOT, $264 \mathrm{p}$. 
Paul, F., KÄÄB, A. \& Haeberli, W. (2007), Recent glacier changes in the Alps observed by satellite: Consequences for future monitoring strategies. Global and Planetary Change, 56 (1-2), 111-122.

Pielke Sr, R. A., Adegoke, J. O., Chase, T. N., Marshall, C. H., Matsui, T. \& Niyogi, D. (2007), A new paradigm for assessing the role of agriculture in the climate system and in climate change. Agricultural and Forest Meteorology, 142 (2-4), 234-254.

Rannow, S., Loibl, W., Greiving, S., Gruehn, D. \& MeYer, B. C. (2010), Potential impacts of climate change in Germany - Identifying regional priorities for adaptation activities in spatial planning. Landscape and Urban Planning, 98 (3-4), 160-171.

Schär, C., Vidale, P. L., Luthi, D., Frei, C., Haberli, C., Liniger, M. A. \& APPENZELLER, C. (2004), The role of increasing temperature variability in European summer heatwaves. Nature, 427 (6972), 332-336.

Vittoz, P., Cherix, D., Gonseth, Y., Lubini, V., Maggini, R., Zbinden, N. \& ZUMBACH, S. (2013), Climate change impacts on biodiversity in Switzerland: A review. Journal for Nature Conservation, 21 (3), 154-162.

Wastl, C., Schunk, C., LüPke, M., Cocca, G., Conedera, M., Valese, E. \& Menzel, A. (2013), Large-scale weather types, forest fire danger, and wildfire occurrence in the Alps. Agricultural and Forest Meteorology, 168, 15-25. 